\title{
A radical reorientation
}

\section{How an annotated book transformed a theoretician into an historian.}

\section{Owen Gingerich}

n 1970 I travelled to Cambridge, England, on a sabbatical leave, little dreaming that

a serendipitous discovery was about to divert my career. The Harvard-Smithsonian reference model for the solar atmosphere had just been published. This was the culmination of a decade of computer work modelling the flow of radiation through stellar atmospheres and exploiting the latest observations made above the Earth's atmosphere by balloons, rockets and satellites. This paper, on which I was lead author, was destined to become a citation classic, and was to be the last straight astrophysics article I ever published. Although my goal - to understand better how science actually works — remained unchanged, an unanticipated turning point radically altered the grist for my mill.

Like many astronomers, I was looking forward to the 1973 quincentennial of the birth of Nicolaus Copernicus, the sixteenthcentury cosmologist who proposed the heliocentric system. I was aware that the novelist Arthur Koestler, in his The Sleepwalkers, had taken Copernicus as his anti-hero and had declared that De revolutionibus orbium coelestium was "the book that nobody read" and "an all-time worstseller". Granted, there are probably more readers alive today than existed in the entire sixteenth century, and Copernicus' treatise is certainly formidably dense and highly mathematical. But was it really true that it had at best only a handful of readers?

In November 1970, I took my family to Scotland for a short holiday and en route I stopped off to discuss Copernicus with a fellow member of the committee planning the international quincentennial celebrations. We pondered the question of the Polish astronomer's readership, and came up with fewer than a dozen names of early astronomers who might have read a major part of it.

Two days later, at the Royal Observatory, Edinburgh, I stumbled on a first-edition De revolutionibus that had been brilliantly annotated from beginning to end. Something seemed curiously improbable. If the book had so few readers, how did it happen that the very next copy of Copernicus' text that I chanced to examine gave evidence of such thorough readership?

Eventually, I was able to identify the handwriting; the extensive marginalia were written at Wittenberg in the sixteenth century by Erasmus Reinhold, the leading astronomy teacher of the generation following

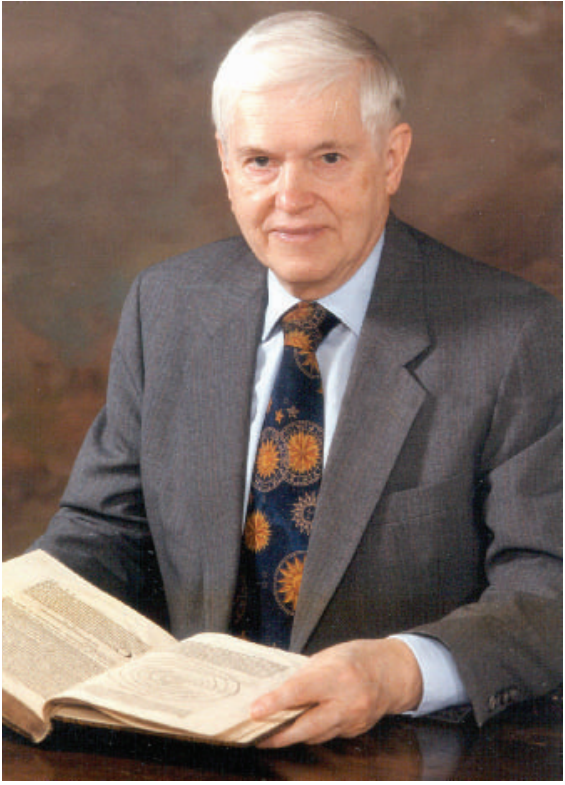

Journey through time and space : Owen Gingerich with his second-edition copy of De revolutionibus.

Copernicus, and one of the names on our shortlist of possible readers.

Undoubtedly, the most fascinating feature of Reinhold's annotations was the motto that he inscribed on the title page: "The Axiom of Astronomy: celestial motions are uniform and circular, or composed of uniform and circular parts." To modern eyes, what a strange summary! Needless to say, no twenty-first-century astronomer would neglect to mention that Copernicus stopped the Sun and made the Earth into a planet, the essence of heliocentrism and the reason why today a first-edition De revolutionibus is a million-dollar icon.

What was going on here? Note that Copernicus had two independent aesthetic ideas, "theories pleasing to the mind" as he called them, for which he had sound philosophical grounds, but no observational proof at all. First was his well-known Sun-centred layout for the planetary system, literally establishing the Solar System. Second was his desire to achieve the required non-uniform orbital motion of the planets by combinations of uniform circular motions, something that appealed greatly to the model-building intentions of sixteenth-century astronomers, but which ultimately proved a dead end. Clearly, Reinhold appreciated the second aesthetic goal, but had understandable reservations about the first. The radical heliocentric cosmology threw the Earth into a dizzying motion that seemed ludicrously contrary to common sense, unsupported by any physics and opposed to the traditional interpretations of holy scripture. The annotations within the book confirmed this stance: remarks on the cosmology were sparse, those on the technical details of the circles copious.

Reinhold's reaction helped solve a long-standing puzzle concerning the very gradual acceptance of the heliocentric blueprint, and it casts light on the reasons why Koestler went astray. With hindsight, we might have expected that astronomers would have immediately adopted Copernicus' vision of the Solar System, as for us it is so obviously the correct arrangement. As post-newtonians, we have no trouble envisioning the Earth as just one of the planetary family. Because the general acceptance of the new cosmology took place only several generations after De revolutionibus was published, Koestler must have jumped to the conclusion that no one had read the book.

The insights afforded by Reinhold's pattern of annotations set me on the trail of further copies of De revolutionibus to see if the book had other readers. What started as a simple research project turned into a fascinating, thirty-year obsession. Studying this turning point in the history of cosmology unexpectedly took my research on the nature of scientific discovery down a very different path.

One obvious conclusion is that Koestler had been dead wrong in saying that it was the book nobody read. De revolutionibus not only had an impressive roster of owners, but many of them read and annotated their copies - however, most of them were reading the book as a manual of geometrical model building, not as a physical description of the cosmos.

With the perspective of history, we can see that a persuasive coherency can finally displace an entrenched world view, but it takes time to build a constituency. The tortoise-like pace of the copernican revolution reflects the radical reorientation of thought required to accept that his "theory pleasing to the mind" described a real, physical universe and was not simply an imaginary device for calculating the positions of the planets.

Owen Gingerich is at the Harvard-Smithsonian

Center for Astrophysics, 60 Garden Street,

Cambridge, Massachusetts 02138, USA.

A fuller account of his copernican adventures appears in The Book Nobody Read: Chasing the Revolutions of Nicolaus Copernicus (Walker, 2004), published in the UK in August (Heinemann, 2004). 